understand the full details of our particular state if we are to have effective medicine. We see the biological exploration of all the genes and the gene variants of the individual human, the record of the ancestors, migrations and kinships, as relevant to our ability to cure, to prescribe drugs tailored to the individual, or to enhance function.

It seems to me that molecular biology is dead. DNA-based thinking has penetrated the whole of biology, and the separate field no longer exists. Also gone is the attempt to answer broad fundamental questions how does DNA work? what controls a gene? - by single individuals. However, in fractal fashion, new sciences appear in the details as we continue to learn. Science is both an individual and a collective endeavour. Like the artist, the creative individual finds new discoveries - most often manifest at the moments of breakthrough when an idea reveals a new field of knowledge - that characterize its forefront. Watson was such an individual, and he has stimulated that character in others.

Walter Gilbert is in the Department of Molecular and Cellular Biology, Harvard University,

Cambridge, Massachusetts 02138, USA.

\section{An astronomical adventure}

\section{The Century of Space Science}

edited by Johan A. M. Bleeker,

Johannes Geiss \& Martin C. E. Huber

Kluwer: 2002. 1,868 pp. E675, \$595, £399

\section{Paul Hodge}

If a publishing house had mentioned to me that it proposed to publish a compendium of 100 essays that covered all of the important topics in space science, totalling nearly 2,000 pages and written by the world's leading space scientists, I would have expressed enthusiasm but great doubt that it could be done. Space scientists are extremely busy people and it would be almost impossible to find an editor with both the prominence and the patience to see such a mammoth project to completion.

But I would have been quite wrong. Kluwer, the publishers of The Century Of Space Science, found not just one but three well-known space scientists to edit the project, and these remarkable men did the job with aplomb. The authors of these well-written and well-illustrated essays include many of the pioneers of space science, as well as many of today's most prestigious practitioners. The result is a truly unique publishing accomplishment: a splendid collection of authoritative reviews that transcends academic disciplines.

Although physically divided into two separate, rather heavy volumes, the material is intellectually divided into three sections: the history and development of space science; stellar space physics and cosmology; and Solar System and Earth science. The first section on the history of space science contains so much fascinating material that it would (almost) be worth carrying around in your briefcase to read on the bus or the train, although the volumes are too heavy to qualify as light reading. The later essays also make good reading, with most striking a nice balance between accessibility and technical detail.

The authors include pioneers such as James van Allen, Cornelius de Jagera and Donald Hunten, as well as more recent contributors to the literature whose names are more familiar. I will single out the impressive contribution of Arturo Russo, who provides a delightful essay on the prehistory of space science (and also an appendix, which I will mention later). I knew a little about Kepler's interest in space travel, but was unaware of Lucian of Samosota's space-based books Vera Historia and Icaro-Menippus, which contain detailed descriptions of space travel to the Moon. This essay describes many other historical items that were also new to me.

It is also fun to read William Hartmann's essay on the status of planetary science at the beginning of the space age — how much has changed in the once almost stagnant field of astronomy! Another essay not to be missed is Herbert Friedman's personal account of his involvement with the beginnings of space-based study of the Earth's ionosphere and upper atmosphere.

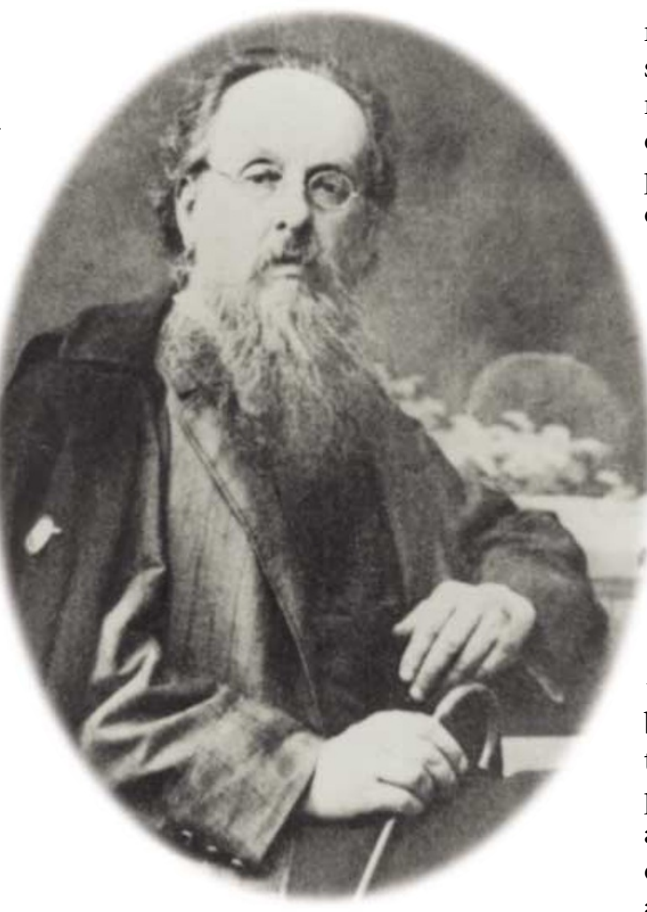

Launching the space age: rocket pioneer K. E. Tsiolkovsky helped space exploration take off.

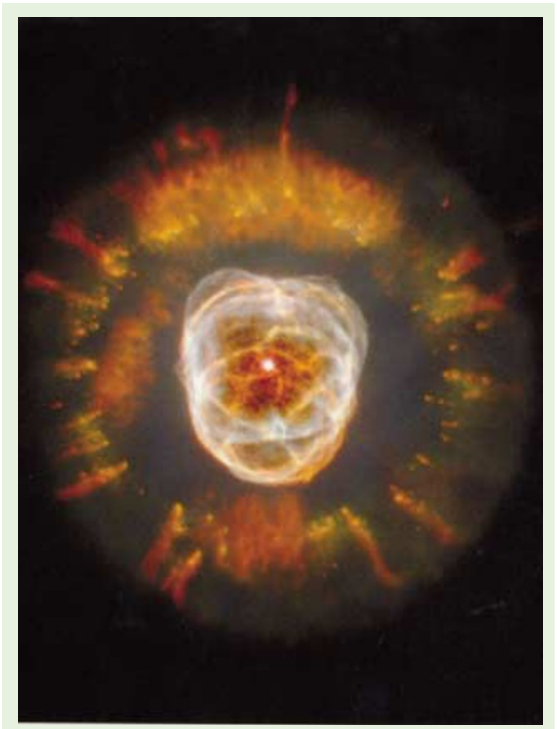

\section{Looking stars in the face}

Advances in telescope technology have opened up whole new worlds and provided glimpses of distant galaxies. The Hubble Space Telescope, in particular, has provided many stunning images, including this snapshot of the Eskimo Nebula in Gemini so called because it resembles a face fringed by a fur parka. It actually consists of a pair of elliptically shaped lobes of gas seen end-on. This image is included in The Times Space: A Photographic Guide to the Universe by Ian Ridpath (HarperCollins, $\mathfrak{E 1 6 . 9 9 ) . ~}$

Space-based results have touched fundamental physics in several ways. Clear, understandable and timely essays about tests of relativity, gravitational lensing, the creation of the elements and the Big Bang are all presented by a list of experts of unarguable distinction. Observational cosmology is also treated well, with comprehensive discussions of such topics as gamma-ray bursts (a hot topic in both senses of the term), quasars and blazars.

One notable landmark is Gustav Tammann's essay on the cosmological constants. Tammann was one of the early advocates of a small Hubble constant (the measure of the rate at which the Universe is expanding). For decades the value of the expansion found by many others seemed to present a contradiction: the expansion age of the Universe seemed to be less than the age obtained by determining the ages of the oldest stars. Tammann's essay presents a clear exposition of this quandary, and shows that current data, based largely on space-based research, provide a reasonable solution, with an age of approximately 14 billion years both for the Universe and also for the stars in it.

A smorgasbord of Earth and planetary 
topics occupies the second volume. As an ignoramus when it comes to our most important star, the Sun, I was fascinated by the status of solar physics. Nine separate essays cover virtually everything recently learned about the physics of the Sun, its interior, and how its outer layers and atmosphere interact with its environment.

It might seem as if the planets are not so well treated, as there are only eight essays concerned with planetary research. However, these essays are comprehensive and well designed; they give the reader an interesting tour of the current state of planetary science. There are also three excellent pieces on comets.

In addition to four flavours of index for acronyms, citations, names and subjects - the back of the second volume includes two appendices that deserve to be widely read, as they bring together information that is otherwise hard to find so neatly in one place. The first is Russo's 'basic chronology of the space age': six pages of space-age highlights, beginning with K. E. Tsiolkovsky's book on space exploration, published in 1903, and ending with the launch of the Soyuz vehicle that took the first crew to the International Space Station in 2000. The second appendix is a tour de force. It is a complete catalogue of space-science launches from 1957 to 2000, with important details of each, listed in a table that occupies an impressive 30 pages of text.

Although the notion of this publishing project would have seemed improbable to me, I have now seen it, lifted it (with some difficulty), and recommend it as an important milestone along the amazing road of space science.

Paul Hodge is in the Department of Astronomy,

University of Washington, Seattle,

Washington 98195, USA.

\section{Ecology out of the blue}

Coral Reef Fishes: Diversity and Dynamics in a Complex Ecosystem edited by Peter Sale

Academic Press: 2002. 724 pp. \$99.95, £69.95

\section{Redouan Bshary}

Peter Sale's first textbook, The Ecology of Fishes on Coral Reefs, became an instant classic for all those who are fascinated by the diversity and complexity of coral-reef fish, their adaptations and their ecology. It left little room for rival textbooks. Now, 11 years on, the steady accumulation of data and ideas has finally warranted a new edition. The title might have changed but fortunately the quality has not.

Coral Reef Fishes is full of fascinating

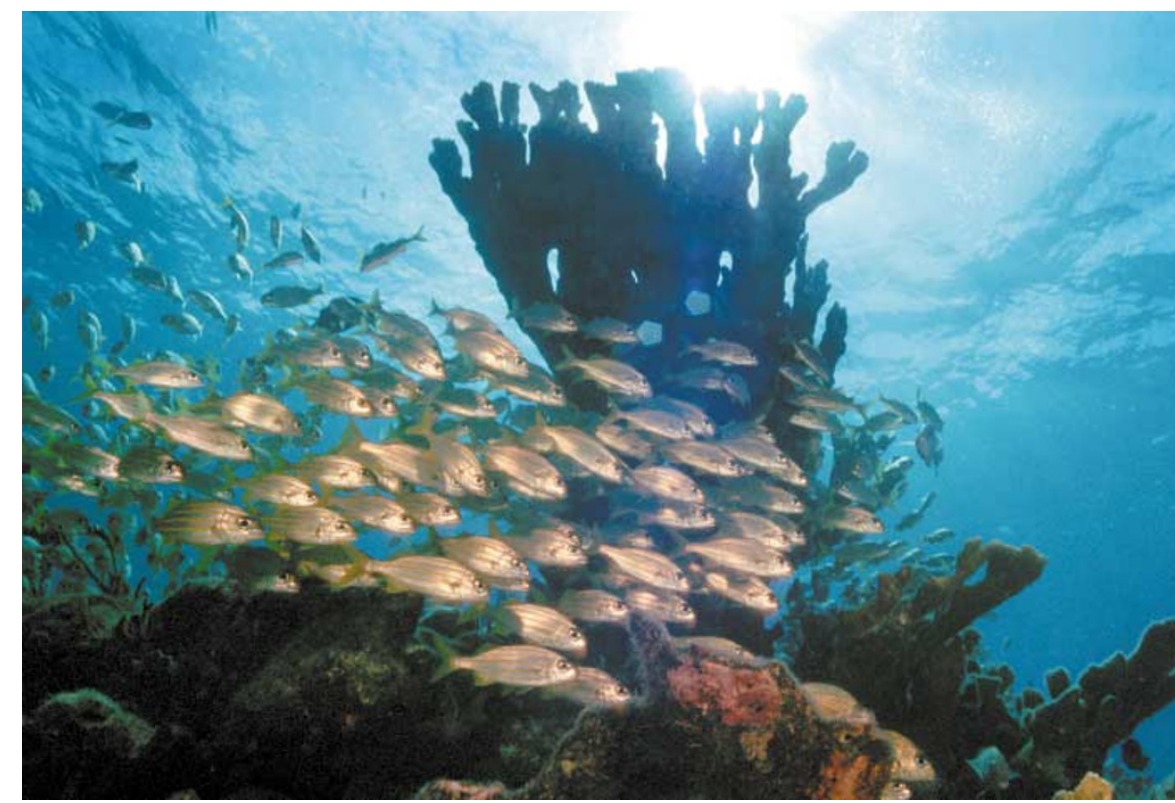

Evolutionarily quiet: these grunts are little changed from their ancestors $\mathbf{5 0}$ million years ago.

details, new evidence and new ideas. For example, we are told that fish on coral reefs 50 million years ago looked very much like they do today (David Bellwood and Peter Wainwright), and that the fish diversity found on coral reefs might largely be due to the constant high temperature, which allows adaptations to exploit low-quality food (Mireille Harmelin-Vivien). Most amazing is the accumulating evidence on the impressive capabilities of reef fish larvae with respect to swimming performance and orientation (Jeffrey Leis and Mark McCormick).

Chapters that describe data at the cutting edge of ecology are well balanced with more 'classical' textbook chapters. There are excellent overviews of reef-fish ecomorphology (Wainwright and Bellwood) and sensory capabilities (Arthur Myrberg and Lee Fuiman), along with critical discussions of methods such as ageing fish using otholits (Howard Choat and Ross Robertson, Simon Thorrold and Jonathan Hare) and population genetics (Serge Planes).

There is certainly plenty of information on coral-reef fish, but this does have one downside: only a few authors (such as Geoffrey Jones, Julian Caley and Philip Munday) try to fit their data into the general framework of ecology and evolution. More comparisons of reef fish with other taxa could have helped to highlight why studying these fish is not only fascinating but also informative and important.

The final section of the book deals with reef-fish conservation issues and the role that ecology might play. There is a frightening honesty about gaps in our ecological knowledge that should be filled for the effective guidance of management decisions (Peter Sale and Garry Russ). But there is also information on the problem of conserving sex-changing species (Phillip Levin and Churchill Grimes) and on the live fish trade, which may promote selective hunting of rare species (Yvonne Sadovy and Amanda Vincent).

So what is the future of coral-reef fish ecology? Two major issues emerge from this book. First, a detailed phylogeny down to the species level, including the ages of lineages, will yield the basis for further sophisticated studies of species diversity and the huge variety in adaptations and specializations found in coral-reef fish. Second, increasing our knowledge of the pelagic (open-water) stages of reef fish is of overwhelming importance for several key issues in ecology and conservation. In particular, knowing more about the degree of local retention of larvae has implications for population dynamics, the potential for sustainable local fishing licences and the design of marine protected areas.

Studies of the pelagic stages might also attract the attention of behavioural ecologists. As it stands, coral-reef fish are suitable subjects for behavioural questions only where fitness proxies (such as energy gain and growth rate) are accepted, such as optimal foraging and cooperation. The study of fish larvae opens the possibility of life-history studies and may even allow assessments of individual fitness. But such projects on fish larvae are likely to be labour-intensive and costly. So, to expand Christopher Peterson and Robert Warner's view, what it takes for behavioural ecologists to join the club is a willingness to think big and to get wet.

Redouan Bshary is at the Max Planck Institute for Behavioural Physiology, Seewiesen, 82319

Starnberg, Germany, and in the Department of Zoology, University of Cambridge, Downing Street, Cambridge CB2 3EJ, UK. 